\title{
Análise dialélica de linhagens de milho quanto à responsividade ao fósforo e à sua eficiência de uso
}

\author{
Walter Fernandes Meirelles(1), Sidney Netto Parentoni(1), Lauro José Moreira Guimarães ${ }^{(1)}$, \\ Paulo Evaristo de Oliveira Guimarães ${ }^{(1)}$, Cleso Antonio Patto Pacheco ${ }^{(2)}$, Antonio Carlos de Oliveira( ${ }^{(1)}$, \\ Flávia Ferreira Mendes ${ }^{(1)}$ e Carlos Alberto Scapim(3)
}

\begin{abstract}
(1)Embrapa Milho e Sorgo, Caixa Postal 151, CEP 35701-970 Sete Lagoas, MG, Brasil. E-mail: walter.meirelles@embrapa.br, sidney.parentoni@embrapa.br, lauro.guimaraes@embrapa.br, paulo.guimaraes@embrapa.br, antoniocarlos.oliveira@embrapa.br, flaviafmendes@yahoo.com.br (2)Embrapa Tabuleiros Costeiros, Caixa Postal 44, CEP 49025-040 Aracaju, SE, Brasil. E-mail: cleso.pacheco@embrapa.br (3)Universidade Estadual de Maringá, Departamento de Agronomia, Avenida Colombo, ํㅡ 5.790, CEP 87020-900 Maringá, PR, Brasil. E-mail: cascapim@uem.br
\end{abstract}

Resumo - O objetivo deste trabalho foi avaliar os efeitos genéticos aditivos e não aditivos sobre a eficiência de uso de $\mathrm{P}$ e a responsividade ao nutriente em linhagens de milho. Nove linhagens contrastantes - eficientes ou não quanto ao uso de $\mathrm{P}$ - foram avaliadas em cruzamentos dialélicos, em delineamento de blocos ao acaso, por dois anos, sob dois níveis de disponibilidade do nutriente em Latossolo Vermelho-Escuro distrófico. As linhagens L3 e L228-3 apresentaram os maiores efeitos médios da capacidade geral de combinação (CGC, $\hat{\mathrm{g}}_{\mathrm{i}}$ ), o que é indício de eficiência, na ausência de P, e de responsividade, na presença. Os cruzamentos L51502020 x L22 e L36 x L56.800.84 apresentaram os maiores efeitos médios da capacidade específica de combinação (CEC, $\hat{\mathrm{s}}_{\mathrm{ij}}$ ), na presença e na ausência de $\mathrm{P}$, respectivamente. Os componentes quadráticos para CGC foram superiores aos da CEC, na ausência de $\mathrm{P}$, e inferiores, na presença, o que mostra que os efeitos aditivos predominaram na eficiência de uso, e os não aditivos, na responsividade ao nutriente. A capacidade combinatória dos genótipos interagiu com os ambientes; portanto, a seleção do melhor progenitor e da melhor combinação híbrida deve ser realizada para ambiente específico. As linhagens apresentam complementariedade gênica quanto à eficiência de uso de P.

Termos para indexação: Zea mays, capacidade específica de combinação, capacidade geral de combinação, complementariedade gênica, eficiência nutricional.

\section{Diallel analysis of maize lines as to their phosphorus responsiveness and use efficiency}

\begin{abstract}
The objective of this work was to evaluate additive and nonadditive genetic effects on P use efficiency and responsiveness to the nutrient in maize lines. Nine contrasting inbred lines - efficient or not regarding $\mathrm{P}$ use efficiency - were evaluated in diallel crosses, in a randomized complete block design, for two years, under two availability levels of the nutrient in an Oxisol. The L3 and L228-3 lines showed the highest average effects for general combining ability (GCA, $\hat{\mathrm{g}}_{\mathrm{i}}$ ), indicating use efficiency in the absence of $\mathrm{P}$, and responsiveness, in the presence. The L51502020 x L22 and L36 x L56.800.84 crosses had the highest average effects for specific combining ability $\left(\mathrm{SCA}, \hat{\mathrm{s}}_{\mathrm{ij}}\right)$ in the presence and in the absence of $\mathrm{P}$, respectively. The quadratic components for GCA were higher than those for SCA, in the absence of $\mathrm{P}$, and lower in the presence, showing that the additive effects predominated in $\mathrm{P}$ use efficiency, and the nonadditive ones predominated in the plant responsiveness to the nutrient. The genotype combining ability interacted with the environments; therefore, the selection of the best parent and of the best hybrid combination should be done in specific environments. The inbred lines show genic complementary action regarding P use efficiency.
\end{abstract}

Index terms: Zea mays, specific combining ability, general combining ability, genic complementary action, nutritional efficiency.

\section{Introdução}

Em pesquisa sobre aquisição de fósforo por plantas de milho, alguns autores observaram que as raízes assumem tamanhos e formas variadas em solo com baixa disponibilidade de $\mathrm{P}$, e que a proporção entre raízes e parte aérea aumenta, para obtenção de maior eficiência na absorção do nutriente (Brasil et al., 
2007). Especificamente para solos brasileiros, foram desenvolvidas metodologias para a adaptação do milho (Zea mays L.) a solos com baixa disponibilidade de P (Parentoni et al., 2004, 2010; Sousa et al., 2012; Mendes et al., 2014). Meirelles (2013) observou também diversidade fenotípica de genótipos de milho quanto à eficiência de uso de $\mathrm{P}$.

A análise dialélica é muito útil na seleção de parentais (Silva et al., 2013). Sprague \& Tatum (1942) relacionaram a capacidade geral de combinação (CGC) à atuação de genes aditivos, e a capacidade específica de combinação (CEC), à de genes dominantes e epistáticos. Este fundamento tem sido utilizado em estudos de herança e controle genético de características importantes para diversas espécies de plantas cultivadas (Hallauer \& Miranda Filho, 1985; Vencovsky \& Barriga, 1992; Cruz et al., 2004; Cruz, 2006; Pinto, 2009; Ramalho et al., 2012; Silva et al., 2013), inclusive em fases iniciais de programas de melhoramento (Scapim et al., 2006b). A análise dialélica de genótipos de milho contrastantes quanto à eficiência de uso do $\mathrm{P}$ permite selecionar genitores mais eficientes no uso e responsivos à aplicação do nutriente, para uso per se, bem como para indicação de híbridos heteróticos, que possam apresentar produção satisfatória em áreas deficientes em $P$.

Em geral, os efeitos gênicos não aditivos predominam quanto à produtividade (Hallauer \& Miranda Filho, 1985; Nihei \& Ferreira, 2012) e eficiência de utilização de P em milho (Fritsche-Neto et al., 2010; DoVale \& Fritsche-Neto, 2013; Mendes et al., 2014). Contudo, alguns dialelos indicam a predominância de efeitos aditivos quanto à produtividade, resistência a doenças e capacidade de expansão do milho-pipoca (Freitas Júnior et al., 2006; Scapim et al., 2006a), resistência à mancha-branca (Nihei \& Ferreira, 2012), e mesmo quanto à eficiência de uso de $\mathrm{P}$ (Meirelles, 2013).

No entanto, Parentoni et al. (2010) mencionam que a herança genética quanto à eficiência de uso de $\mathrm{P}$ em milho tropical ainda merece mais estudos, especialmente porque esta herança, normalmente, tem sido estudada em um único ambiente, sem que se dê a necessária ênfase sobre a importância da avaliação em diferentes condições de solo. Portanto, são oportunos os trabalhos que empreguem ambientes contrastantes, no sentido de se explorar melhor a variabilidade genotípica, para que seja possível fornecer informações mais reais sobre a herança.
O objetivo deste trabalho foi avaliar os efeitos genéticos aditivos e não aditivos sobre a eficiência de uso de $\mathrm{P}$ e a responsividade ao nutriente em linhagens de milho, em Latossolo com diferentes disponibilidades do nutriente.

\section{Material e Métodos}

Nove linhagens endogâmicas de milho, previamente selecionadas pela Embrapa quanto à eficiência de uso de $\mathrm{P}$, foram utilizadas (Tabela 1). Apenas as linhagens L3 e L228-3 eram linhagens elite, selecionadas por sua boa capacidade combinatória e pela presença de bons atributos agronômicos. As linhagens L3, L228-3 e L36 são consideradas eficientes em dialelos conduzidos em solos com alta e baixa disponibilidade de $\mathrm{P}$, enquanto as linhagens L22 e L53 são ineficientes em solos com baixa disponibilidade de $\mathrm{P}$ (Parentoni et al., 2010).

O plantio do milho, para a seleção de linhagens eficientes a baixo $\mathrm{P}$, foi realizado em Latossolo Vermelho-Escuro distrófico, fase cerrado, com 500$600 \mathrm{~g} \mathrm{~kg}^{-1}$ de argila, e os seguintes resultados da análise química: $\mathrm{P}, 2,0 \mathrm{mg} \mathrm{kg}^{-1} ; \mathrm{pH}$ de 4,8 a 5,2; e matéria orgânica, $48 \mathrm{~g} \mathrm{~kg}^{-1}$ (Meirelles, 2013). Consideraramse responsivos os genótipos que atingiram alta produtividade com teores normais de $\mathrm{P}$ no solo. Os híbridos 2B707, P 30F35, DKB 390 e AG 7088, responsivos às adubações, e BRS 1055 e BRS 1060, obtidos de linhagens com uso eficiente de $\mathrm{P}$, foram utilizados como testemunhas.

Os cruzamentos seguiram um esquema de dialelo completo, em que as linhagens constituíram um modelo fixo. As nove linhagens parentais foram semeadas em fileiras de $3,0 \mathrm{~m}$, para obtenção de $600 \mathrm{~g}$ de sementes para cada $\mathrm{F}_{1}$. Os experimentos de avaliação continham $36 \mathrm{~F}_{1}$ 's e seis testemunhas, no total de 42 tratamentos instalados na Embrapa Milho e Sorgo, em Sete Lagoas, MG, nos anos de 2010/2011 e 2011/2012. As semeaduras foram realizadas em $2 / 11 / 2010$ e 17/1/2012. Em cada ano, avaliaram-se dois experimentos semelhantes, com e sem P na adubação de semeadura.

A instalação dos experimentos de avaliação ocorreu em duas áreas separadas, com mesma classe de solo, datas de semeadura, população de plantas e tratos culturais, porém com disponibilidades diferentes de P. Na primeira área, o solo foi corrigido e apresentava alta disponibilidade de $\mathrm{P}\left(18,84 \mathrm{mg} \mathrm{kg}^{-1}\right)$. A segunda 
área tinha o mesmo tipo de solo, porém, com baixa disponibilidade de $\mathrm{P}\left(2,57 \mathrm{mg} \mathrm{kg}^{-}\right)$, típico de cerrado natural, sem fosfatagem corretiva prévia. $\mathrm{O} \mathrm{pH}$ das áreas foi de 6,2 e 5,2, respectivamente. Os dois experimentos utilizaram diferentes adubações com P: a primeira área recebeu $\mathrm{P}$ na adubação de semeadura a $112 \mathrm{~kg} \mathrm{ha}^{-1}$ de $\mathrm{P}_{2} \mathrm{O}_{5}$, o que correspondeu a $400 \mathrm{~kg} \mathrm{ha}^{-1} \mathrm{da}$ fórmula 8-28-16 (NPK). Assim, a adubação com essa fórmula forneceu ainda $32 \mathrm{~kg} \mathrm{ha}^{-1}$ de $\mathrm{N}$ e $64 \mathrm{~kg} \mathrm{ha}^{-1}$ de $\mathrm{K}_{2} \mathrm{O}$. Na segunda área, nenhum $\mathrm{P}$ foi adicionado, tendo-se utilizado, no entanto, as mesmas dosagens de $\mathrm{N}$ e $\mathrm{K}$ fornecidas na primeira área. Ambas as áreas receberam adubação em cobertura com $90 \mathrm{~kg} \mathrm{ha}^{-1} \mathrm{de} \mathrm{N}$.

A parcela experimental consistiu de uma fileira de 4,0 m, com espaçamento de $0,80 \mathrm{~m}$ entre as fileiras. Utilizou-se o delineamento de blocos ao acaso, com três repetições. Quarenta sementes foram semeadas, com espaçamento de $20 \mathrm{~cm}$ entre as sementes. $\mathrm{O}$ desbaste foi realizado para garantir 20 plantas por fileira, equivalente a 62.500 plantas por hectare. A análise de variância utilizou a massa de grãos - em quilogramas por parcela transformados em quilogramas por hectare - corrigida para $13 \%$ de umidade. A análise preliminar foi feita com o programa SAS, versão 9.2 para Windows (SAS Institute Inc., Cary, NC, EUA). A magnitude das interações genótipos por ambientes (GxA) foi obtida na análise conjunta, de acordo com avaliações em dois anos (Vencovsky \& Barriga, 1992). As médias dos tratamentos foram agrupadas pelo teste de Scott-Knott, a 5\% de probabilidade.

Para a análise dialélica, utilizou-se o programa Genes 6.1 (Cruz, 2006, 2013), com base no modelo estatístico de dialélicos exposto por Cruz et al. (2004), que segue o método 4 desenvolvido por Griffing (1956).
Esse método inclui apenas híbridos $\mathrm{F}_{1}$ 's e estima os efeitos da capacidade geral e específica de combinação conforme o seguinte modelo: $\mathrm{Y}_{\mathrm{ij}}=\mathrm{m}+\mathrm{g}_{\mathrm{i}}+\mathrm{g}_{\mathrm{j}}+\mathrm{s}_{\mathrm{ij}}+\varepsilon_{\mathrm{ij}}$, em que: $Y_{\mathrm{ij}}$ é o valor médio da combinação híbrida ij; $\mathrm{m}$, o efeito médio geral de todos os $\mathrm{F}_{1}$ 's do dialelo; $\mathrm{g}_{\mathrm{i}}$ e $\mathrm{g}_{\mathrm{j}}$ são os efeitos da capacidade geral de combinação do i-ésimo e j-ésimo progenitores, respectivamente; $\mathrm{s}_{\mathrm{ij}}$ é o efeito da capacidade específica de combinação para os cruzamentos com os progenitores i e j; e $\varepsilon_{\mathrm{ij}}$ é o erro experimental médio associado às médias da tabela dialélica.

\section{Resultados e Discussão}

A produtividade média com adubação de $\mathrm{P}$ foi de 10.235 e $7.499 \mathrm{~kg} \mathrm{ha}^{-1} \mathrm{em} 2011$ e 2012, respectivamente; e de 4.294 e $3.588 \mathrm{~kg} \mathrm{ha}^{-1}$, sem P (Tabela 2). No segundo ano, as menores produtividades decorreram da menor precipitação, que foi de 913,2, em 2011, e de 418,2 mm, em 2012. Os coeficientes de variação foram menores no experimento com adubação de $\mathrm{P}$, em ambos os anos. No experimento sem adubação com $\mathrm{P}$, algumas plantas, de alguns genótipos, não se desenvolveram, o que comprometeu o estande final médio.

A interação GxA significativa $\left(1,69^{*}\right.$ e $3,27^{* *}$ para presença e ausência de $\mathrm{P}$ na semeadura) evidenciou comportamento distinto entre os híbridos, nos dois anos. A análise de variância conjunta, para médias agrupadas dos anos de 2011 e 2012, mostrou que os híbridos diferiram entre si (Tabela 3). Houve nítida diferença entre os ambientes, e o teste $\mathrm{F}$ mostrou alta variabilidade em relação ao erro experimental, o que é interessante para a qualidade experimental (Resende $\&$ Duarte, 2007). A precipitação distinta entre os anos

Tabela 1. Origem, ano de obtenção e grau de eficiência no uso de $\mathrm{P}$ das linhagens endogâmicas de milho utilizadas como genitoras nos cruzamentos dialélicos.

\begin{tabular}{|c|c|c|c|c|}
\hline Genitor & Linhagem & Origem & Ano de obtenção & Eficiência no uso de P \\
\hline 1 & L 3 & Sintético eficiente em uso de fósforo & 1999 & Altamente eficiente \\
\hline 2 & L 228-3 & Sintético BR 106 & 1995 & Eficiente \\
\hline 3 & L36 & Sintético de híbridos comerciais & 1983 & Medianamente Eficiente \\
\hline 4 & L 56.800 .79 & Sintético de híbridos para Cerrado & 2003 & Eficiente \\
\hline 5 & L 51502020 & $($ CMS $5046 \times$ L20) x L20 & - & Eficiente \\
\hline 6 & L 56.800 .84 & Sintético de híbridos para Cerrado & 2003 & Eficiente \\
\hline 7 & $\mathrm{~L} 22$ & BR 106 & 1983 & Ineficiente \\
\hline 8 & L 53 & BR 111 & 1980 & Ineficiente \\
\hline 9 & L 56.800 .67 & Sintético de híbridos para Cerrado & 2003 & Ineficiente \\
\hline
\end{tabular}


Tabela 2. Produtividade de grãos e efeito da capacidade específica de combinação ( $\left.\hat{\mathrm{s}}_{\mathrm{i}}, \mathrm{CEC}\right)$ quanto à eficiência de uso do $\mathrm{P}$ pelo milho, com ou sem o uso de P na adubação de semeadura, nos anos de 2011 e $2012^{(1)}$.

\begin{tabular}{|c|c|c|c|c|c|c|c|c|c|c|}
\hline \multirow[t]{3}{*}{ Genótipo } & \multicolumn{4}{|c|}{ Produtividade $\left(\mathrm{kg} \mathrm{ha}^{-1}\right)$} & \multicolumn{6}{|c|}{ Efeitos $\hat{S}_{\mathrm{ij}}$} \\
\hline & \multicolumn{2}{|c|}{ Com P } & \multicolumn{2}{|c|}{ Sem P } & \multicolumn{2}{|c|}{ Com P } & \multirow{2}{*}{$\begin{array}{l}\text { Efeitos } \\
\text { médios }\end{array}$} & \multicolumn{2}{|c|}{ Sem P } & \multirow{2}{*}{$\begin{array}{l}\text { Efeitos } \\
\text { médios }\end{array}$} \\
\hline & 2011 & 2012 & 2011 & 2012 & 2011 & 2012 & & 2011 & 2012 & \\
\hline $1 \times 2$ & $12.879 a$ & $8.520 \mathrm{a}$ & $5.112 \mathrm{~b}$ & $4.504 \mathrm{a}$ & $1.661,38$ & 195,32 & 928,35 & $-241,79$ & 202,74 & $-19,53$ \\
\hline $1 \times 3$ & $11.111 \mathrm{~b}$ & $6.727 \mathrm{~b}$ & $5.623 \mathrm{a}$ & $3.076 \mathrm{~b}$ & 301,00 & $-905,66$ & $-302,33$ & 9,08 & $-583,23$ & $-287,08$ \\
\hline $1 \times 4$ & $8.658 \mathrm{~d}$ & $7.774 \mathrm{~b}$ & $4.345 \mathrm{c}$ & $4.235 \mathrm{a}$ & $-1.103,15$ & 905,12 & $-99,02$ & $-50,16$ & $-459,53$ & $-254,85$ \\
\hline $1 \times 5$ & $8.931 d$ & $5.731 \mathrm{~b}$ & $5.620 \mathrm{a}$ & $4.478 \mathrm{a}$ & $-2.186,59$ & $-1.963,78$ & $-2.075,18$ & 267,65 & 415,18 & 341,42 \\
\hline $1 \times 6$ & $9.537 \mathrm{c}$ & $7.361 \mathrm{~b}$ & $4.278 \mathrm{c}$ & $5.605 \mathrm{a}$ & 270,64 & $1.087,78$ & 679,21 & $-259,91$ & $1.373,84$ & 556,97 \\
\hline $1 \times 7$ & $10.436 \mathrm{c}$ & $8.562 \mathrm{a}$ & $5.349 \mathrm{~b}$ & $4.137 \mathrm{a}$ & 170,60 & 891,32 & 530,96 & 448,17 & 547,33 & 497,75 \\
\hline $1 \times 8$ & $10.633 c$ & $6.566 \mathrm{~b}$ & $5.758 \mathrm{a}$ & $2.270 \mathrm{~b}$ & 602,89 & $-225,40$ & 188,74 & $1.049,09$ & $-760,79$ & 144,15 \\
\hline $1 \times 9$ & $10.258 \mathrm{c}$ & $8.446 \mathrm{a}$ & $4.628 \mathrm{~b}$ & $3.636 \mathrm{~b}$ & 283,23 & 15,31 & 149,27 & $-1.222,12$ & $-735,55$ & $-978,83$ \\
\hline $2 \times 3$ & $11.200 \mathrm{~b}$ & $9.207 \mathrm{a}$ & $3.775 \mathrm{c}$ & $2.796 b$ & $-47,28$ & 863,37 & 408,04 & $-700,23$ & $-479,23$ & $-589,73$ \\
\hline $2 \times 4$ & $10.337 \mathrm{c}$ & $7.596 \mathrm{~b}$ & $3.899 \mathrm{c}$ & $5.184 \mathrm{a}$ & 138,30 & 15,76 & 77,03 & 642,82 & 873,46 & 758,14 \\
\hline $2 \times 5$ & $12.411 \mathrm{a}$ & $8.863 \mathrm{a}$ & $5.410 \mathrm{~b}$ & $3.235 \mathrm{~b}$ & 855,85 & 456,52 & 656,19 & $1.196,39$ & $-443,59$ & 376,40 \\
\hline $2 \times 6$ & $8.739 d$ & $7.013 b$ & $3.083 \mathrm{~d}$ & $3.461 \mathrm{~b}$ & $-964,19$ & 28,31 & $-467,94$ & $-316,25$ & $-385,69$ & $-350,97$ \\
\hline $2 \times 7$ & $9.394 c$ & $6.016 \mathrm{~b}$ & $3.862 \mathrm{c}$ & $2.332 b$ & $-1.308,92$ & $-2.365,44$ & $-1.837,18$ & 100,37 & $-872,77$ & $-386,20$ \\
\hline $2 \times 8$ & $9.903 c$ & $7.109 \mathrm{~b}$ & $2.573 \mathrm{~d}$ & $2.180 \mathrm{~b}$ & $-565,12$ & $-393,80$ & $-479,46$ & $-997,02$ & $-466,79$ & $-731,91$ \\
\hline $2 \times 9$ & $10.643 \mathrm{c}$ & $10.342 \mathrm{a}$ & $5.027 \mathrm{~b}$ & $5.559 \mathrm{a}$ & 229,98 & $1.199,97$ & 714,98 & 315,72 & $1.571,88$ & 943,80 \\
\hline $3 \times 4$ & $9.899 \mathrm{c}$ & $6.032 \mathrm{~b}$ & $3.671 \mathrm{c}$ & $3.601 \mathrm{~b}$ & 108,49 & $-855,59$ & $-373,55$ & 154,01 & $-67,41$ & 43,30 \\
\hline $3 \times 5$ & $11.298 b$ & $8.606 \mathrm{a}$ & $3.805 \mathrm{c}$ & $3.162 b$ & 150,90 & 891,77 & 521,33 & $-668,55$ & 125,48 & $-271,53$ \\
\hline $3 \times 6$ & $9.706 \mathrm{c}$ & $7.019 \mathrm{~b}$ & $4.798 \mathrm{~b}$ & $4.322 \mathrm{a}$ & 410,60 & 726,80 & 568,70 & $1.138,49$ & $1.116,84$ & $1.127,66$ \\
\hline $3 \times 7$ & $9.270 \mathrm{~d}$ & $5.579 \mathrm{~b}$ & $3.202 \mathrm{c}$ & $1.721 \mathrm{~b}$ & $-1.023,81$ & $-2.110,43$ & $-1.567,12$ & $-819,64$ & $-842,68$ & $-831,16$ \\
\hline $3 \times 8$ & $10.013 \mathrm{c}$ & $7.471 \mathrm{~b}$ & $3.668 \mathrm{c}$ & $2.032 b$ & $-46,89$ & 660,85 & 306,98 & $-162,26$ & 27,53 & $-67,37$ \\
\hline $3 \times 9$ & $10.151 \mathrm{c}$ & $9.179 \mathrm{a}$ & $6.021 \mathrm{a}$ & $4.048 \mathrm{a}$ & 146,99 & 728,90 & 437,94 & $1.049,10$ & 702,70 & 875,90 \\
\hline $4 \times 5$ & $10.613 c$ & $7.252 \mathrm{~b}$ & $3.053 \mathrm{~d}$ & $3.939 \mathrm{a}$ & 515,26 & 302,46 & 408,86 & $-201,45$ & $-132,68$ & $-167,07$ \\
\hline $4 \times 6$ & $7.460 \mathrm{~d}$ & $4.870 \mathrm{~b}$ & $2.657 \mathrm{~d}$ & $3.248 \mathrm{~b}$ & $-786,30$ & $-658,26$ & $-722,28$ & 216,68 & $-992,56$ & $-387,94$ \\
\hline $4 \times 7$ & $10.339 \mathrm{c}$ & $8.238 \mathrm{a}$ & $3.366 \mathrm{c}$ & $4.841 \mathrm{a}$ & $1.093,22$ & $1.312,39$ & $1.202,81$ & 562,90 & $1.241,93$ & 902,42 \\
\hline $4 \times 8$ & $9.715 \mathrm{c}$ & $6.012 \mathrm{~b}$ & $2.867 \mathrm{~d}$ & $3.550 \mathrm{~b}$ & 704,05 & $-34,47$ & 334,79 & 256,40 & 509,54 & 382,97 \\
\hline $4 \times 9$ & $8.286 \mathrm{~d}$ & $6.699 \mathrm{~b}$ & $2.172 \mathrm{~d}$ & $3.408 \mathrm{~b}$ & $-669,87$ & $-987,40$ & $-828,64$ & $-1.581,20$ & $-972,75$ & $-1.276,98$ \\
\hline $5 \times 6$ & $9.606 \mathrm{c}$ & $6.008 \mathrm{~b}$ & $3.587 \mathrm{c}$ & $3.098 \mathrm{~b}$ & 2,82 & $-346,55$ & $-171,87$ & 189,27 & $-510,59$ & $-160,66$ \\
\hline $5 \times 7$ & $12.094 \mathrm{~b}$ & $8.818 \mathrm{a}$ & $3.206 \mathrm{c}$ & $3.170 \mathrm{~b}$ & $1.491,98$ & $1.066,49$ & $1.279,23$ & $-554,07$ & 203,25 & $-175,41$ \\
\hline $5 \times 8$ & $9.560 \mathrm{c}$ & $7.266 \mathrm{~b}$ & $3.331 \mathrm{c}$ & $2.422 b$ & $-807,02$ & 393,22 & $-206,90$ & $-237,23$ & 13,89 & $-111,67$ \\
\hline $5 \times 9$ & $10.289 \mathrm{c}$ & $7.712 \mathrm{~b}$ & $4.718 b$ & $4.078 \mathrm{a}$ & $-23,20$ & $-800,13$ & $-411,66$ & 7,98 & 329,05 & 168,52 \\
\hline $6 \times 7$ & $9.588 \mathrm{c}$ & $6.188 \mathrm{~b}$ & $2.590 \mathrm{~d}$ & $2.849 \mathrm{~b}$ & 837,34 & $-142,08$ & 347,63 & $-356,08$ & $-286,12$ & $-321,10$ \\
\hline $6 \times 8$ & $8.877 \mathrm{~d}$ & $5.540 \mathrm{~b}$ & $1.880 \mathrm{~d}$ & $2.995 b$ & 360,87 & 88,35 & 224,61 & $-873,38$ & 418,06 & $-227,66$ \\
\hline $6 \times 9$ & $8.329 \mathrm{~d}$ & $6.306 \mathrm{~b}$ & $4.157 \mathrm{c}$ & $3.184 b$ & $-131,76$ & $-784,35$ & $-458,06$ & 261,19 & $-733,78$ & $-236,30$ \\
\hline $7 \times 8$ & $8.678 d$ & $6.964 b$ & $3.323 \mathrm{c}$ & $2.150 \mathrm{~b}$ & $-836,91$ & 115,66 & $-360,63$ & 206,72 & 214,58 & 210,65 \\
\hline $7 \times 9$ & $9.036 \mathrm{~d}$ & $9.720 \mathrm{a}$ & $4.670 \mathrm{~b}$ & $3.070 \mathrm{~b}$ & $-423,51$ & $1.232,10$ & 404,30 & 411,64 & $-205,52$ & 103,06 \\
\hline $8 \times 9$ & $9.813 c$ & $7.005 \mathrm{~b}$ & $4.824 b$ & $2.761 \mathrm{~b}$ & 588,13 & $-604,41$ & $-8,14$ & 757,69 & 43,98 & 400,83 \\
\hline $2 \mathrm{~B} 707$ & $11.185 b$ & $9.649 \mathrm{a}$ & $5.925 \mathrm{a}$ & $4.121 \mathrm{a}$ & - & - & - & - & - & - \\
\hline P 30F35 & $12.843 \mathrm{a}$ & $6.526 \mathrm{~b}$ & $6.606 \mathrm{a}$ & $5.218 \mathrm{a}$ & - & - & - & - & - & - \\
\hline DKB 390 & $10.655 \mathrm{c}$ & $9.048 \mathrm{a}$ & $6.345 \mathrm{a}$ & $4.721 \mathrm{a}$ & - & - & - & - & - & - \\
\hline AG 7088 & $11.902 b$ & $9.758 \mathrm{a}$ & $5.415 \mathrm{~b}$ & $4.179 \mathrm{a}$ & - & - & - & - & - & - \\
\hline BRS 1055 & $13.831 \mathrm{a}$ & $7.951 \mathrm{a}$ & $5.287 \mathrm{~b}$ & $4.656 \mathrm{a}$ & - & - & - & - & - & - \\
\hline BRS 1060 & $11.789 \mathrm{~b}$ & $7.687 \mathrm{~b}$ & $6.847 \mathrm{a}$ & $3.468 \mathrm{~b}$ & - & - & - & - & - & - \\
\hline Média geral & 10.235 & 7.499 & 4.294 & 3.588 & - & - & - & - & - & - \\
\hline Média $F_{1}$ 's & 9.936 & 7.342 & 3.998 & 3.454 & - & - & - & - & - & - \\
\hline QM resíduo & 816.340 & 1.425 .333 & 689.694 & 643.035 & - & - & - & - & - & - \\
\hline $\mathrm{CV}(\%)$ & 8,83 & 15,92 & 19,34 & 22,35 & - & - & - & - & - & - \\
\hline$\overline{\mathrm{DP}}\left(\hat{\mathrm{s}}_{\mathrm{ij}}\right)$ & & & & & 451,76 & 596,94 & - & 415,24 & 400,95 & - \\
\hline$D P\left(\hat{s}_{i j}-\hat{s}_{i k}\right)$ & & & & & 682,99 & 902,48 & - & 627,78 & 606,18 & - \\
\hline $\operatorname{DP}\left(\hat{s}_{i j}-\hat{S}_{k l}\right)$ & & & & & 623,48 & 823,85 & - & 573,08 & 553,36 & - \\
\hline
\end{tabular}

${ }^{(1)}$ Médias seguidas de letras iguais pertencem ao mesmo agrupamento, pelo teste Scott-Knott, a 5\% de probabilidade. QM, quadrado médio; DP, desvio-padrão. 
contribuiu para maiores diferenças entre efeito de ambientes do que entre os efeitos dos genótipos.

De acordo com o modelo fixo, as conclusões a respeito dos efeitos de tratamentos (efeitos fixos) interessam somente ao grupo de genótipos estudados (Cruz et al., 2004). Assim, a produtividade dos genótipos foi avaliada em cada ambiente, em razão da interação GxA, e o agrupamento de médias apontou diferenças significativas entre eles (Tabela 2). As testemunhas apresentaram boa produtividade. O cruzamento $1 \times 2$ (L3 x L228-3) sobressaiu-se em termos de produtividade e de responsividade a $\mathrm{P}$, e seu desempenho não diferiu das melhores testemunhas na presença do nutriente. O cruzamento $2 \times 9$ (L228-3 x L56.800.67) obteve alta produtividade e eficiência de uso do P, em 2012, além de bom desempenho produtivo relativo, na presença de $\mathrm{P}$, e boa eficiência, na ausência. Outras combinações híbridas apresentaram destaque produtivo em situações específicas de ambiente (ano de cultivo) e de disponibilidade de $\mathrm{P}$, nas quais se equipararam estatisticamente às melhores testemunhas.

A seleção do valor genotípico é mais segura com avaliações em diferentes ambientes (Ramalho et al., 2012), mas o usual, na análise dialélica, é utilizar médias de ambientes (Cruz, 2006), conforme feito aqui, na análise dialélica conjunta (Tabela 3). Esta análise considera as interações ambientais e foi realizada com médias acumuladas dos anos de 2011 e 2012, que permitiram a determinação dos componentes quadráticos para os tratamentos, bem como sua decomposição em termos da capacidade combinatória (Cruz et al., 2004) para a obtenção dos efeitos de CGC e CEC para os 36 F $_{1}$ 's (Griffing, 1956).

Os efeitos da CGC foram significativos na presença de $\mathrm{P}$, e os da CEC foram significativos tanto na presença como na ausência de $\mathrm{P}$, o que indica presença tanto de efeitos aditivos como de não aditivos na expressão da eficiência ao uso de P. A magnitude do quadrado médio (QM) da CGC foi sempre superior ao da CEC, mas esta relação tem menor importância do que os componentes quadráticos $\left(\hat{\Phi}_{\mathrm{g}} \mathrm{e} \hat{\Phi}_{\mathrm{s}}\right)$, que expressam a variabilidade dos genótipos e estimam melhor os efeitos aditivos e não aditivos (Cruz, 2006). Os componentes quadráticos da CGC foram superiores aos da CEC, na ausência de P, mas inferiores na presença do nutriente na semeadura; $\mathrm{o}$ que realça a importância tanto dos efeitos aditivos como dos não aditivos na utilização de $\mathrm{P}$ (Tabela 3 ). Em geral, efeitos não aditivos predominam na produtividade em milho (Freitas Júnior et al., 2006; Scapim et al., 2006a; Nihei \& Ferreira, 2012), mas alguns dialelos indicam também efeitos aditivos (Aguiar et al., 2003; Scapim et al., 2006b; Souza et al., 2008; Meirelles, 2013). Nos dialelos, utilizam-se desde linhagens endogâmicas até variedades de base genética ampla (Hallauer \& Miranda Filho, 1985). Assim, diferentes genes podem expressar características desejáveis, e cada genitor participa com maior ou menor frequência de genes

Tabela 3. Análises dialélicas conjuntas das médias acumuladas de produtividade de grãos (kg ha $\left.{ }^{-1}\right)$ de milho de 2011 e 2012 , para avaliação da eficiência de uso do P.

\begin{tabular}{|c|c|c|c|c|c|}
\hline \multirow[t]{2}{*}{ Fonte de variação } & \multirow[t]{2}{*}{ GL } & \multicolumn{2}{|c|}{ Com P na semeadura } & \multicolumn{2}{|c|}{ Sem P na semeadura } \\
\hline & & QM & $\mathrm{F}$ & QM & $\mathrm{F}$ \\
\hline Tratamento & 35 & 7.216 .211 & $3,81 * *$ & 4.208 .955 & $1,93 *$ \\
\hline CGC & 8 & 16.591 .364 & $5,11^{*}$ & 10.413 .218 & $1,83^{\mathrm{ns}}$ \\
\hline CEC & 27 & 4.438 .388 & $2,97 * *$ & 2.370 .655 & $2,08^{*}$ \\
\hline Ambiente & 1 & 363.225 .144 & $191,52 * *$ & 15.957 .160 & $7,33^{*}$ \\
\hline Tratamento $\mathrm{x}$ ambiente & 35 & 1.896 .497 & $1,69^{*}$ & 2.177 .348 & $3,27 * *$ \\
\hline CGC $\mathrm{x}$ ambiente & 8 & 3.245 .884 & $2,90 * *$ & 5.679 .705 & $8,52 * *$ \\
\hline CEC $x$ ambiente & 27 & 1.496 .679 & $1,34^{\mathrm{ns}}$ & 1.139 .612 & $1,71 *$ \\
\hline Resíduo & 164 & 1.120 .837 & - & 666.365 & - \\
\hline Média geral & & 8.639 & - & 3.726 & - \\
\hline \multicolumn{6}{|c|}{ Componentes quadráticos médios } \\
\hline CGC & & 341.659 & - & 216.202 & - \\
\hline CEC & & 366.119 & - & 172.988 & - \\
\hline Resíduo & & 1.120 .837 & - & 666.365 & - \\
\hline
\end{tabular}

${ }^{n}$ Não significativo. * e **Significativo, a 5 e 1\% de probabilidade, respectivamente, pelo teste Scott-Knott. CGC, capacidade geral de combinação; CEC, capacidade específica de combinação. 
favoráveis. Deste modo, a existência de maior ou menor variabilidade e divergência entre os genitores - evidenciada na heterose obtida nos cruzamentos - pode proporcionar resultados contrastantes quanto ao tipo de ação gênica predominante para a característica. A predominância de efeitos aditivos também ocorre em outras características, como arquitetura de plantas em feijão (Silva et al., 2013), eficiência do uso de N (Souza et al., 2008; DoVale et al., 2012) e eficiência do uso de P em milho (Meirelles, 2013).

Se efeitos aditivos predominam na eficiência de uso, como ocorreu na ausência de P na semeadura, sugerese como orientação para a metodologia de seleção a utilização das linhagens com maior efeito $\hat{g}_{i}$, com os seguintes objetivos: formar populações sintéticas para autofecundações; reciclar linhagens-elite; aumentar de forma recorrente a frequência de genes favoráveis nas populações melhoradas; e possibilitar o cruzamento das melhores linhagens divergentes, para obtenção de novas combinações heteróticas.

No entanto, com a presença de $\mathrm{P}$ na semeadura, predominaram os efeitos não aditivos. Parentoni et al. (2010) concluíram que os efeitos de dominância predominam na eficiência de aquisição de $\mathrm{P}$, em milho tropical avaliado no Cerrado. $\mathrm{O}$ estresse ocasionado pela baixa disponibilidade de $\mathrm{P}$ e a deficiência do nutriente no metabolismo afetam processos de absorção, translocação, assimilação e redistribuição de $\mathrm{P}$ na planta, o que modifica a resposta produtiva dos genótipos (Marschner, 1995). Além disso, interações benéficas com fungos micorrízicos podem conferir maior eficiência a alguns genótipos; alterações morfológicas radiculares também podem estar relacionadas à maior adaptação de alguns genótipos a condições de baixa disponibilidade de P (Brasil et al., 2007; Meirelles, 2013). Assim, a manifestação ambiental tanto acrescenta variação ao erro experimental como pode promover efeitos genéticos diferenciados em cada grupo de genótipos. Quando os efeitos da CEC superam os da CGC, sugere-se a utilização de híbridos (Hallauer \& Miranda Filho, 1985; Cruz et al., 2004).

Os componentes quadráticos mostraram a superioridade dos efeitos da CGC, na ausência de P na semeadura, o que evidencia concentração de genes predominantemente aditivos. Uma razão para este fato é que as linhagens foram escolhidas apenas por suas características intrínsecas, de eficiência ou ineficiência do uso de $\mathrm{P}$, e não representaram grupos heteróticos opostos, o que ampliaria os efeitos da CEC.

Na deficiência de $\mathrm{P}$, o metabolismo da planta se altera afetando processos produtivos (Marschner, 1995), o que confere adaptação diferenciada dos genótipos ao ambiente. Esta influência ambiental pode afetar a resposta heterótica e promover efeitos genéticos distintos nos dialelos. A manifestação heterótica, por sua vez, está relacionada ao grau de divergência genética e à frequência gênica (Cruz \& Vencovsky, 1989). No presente estudo, o fato de as linhagens genitoras não terem sido escolhidas conforme suas divergências genéticas pode ter favorecido a predominância dos efeitos aditivos na produtividade. Aguiar et al. (2003) encontraram tanto efeitos aditivos (CGC) como não aditivos (CEC) na produção de milho, em que parte dos genes apresentava ação dominante, com o melhor hibrido simples formado por linhagens de grupos heteróticos distintos. Sprague \& Tatum (1942) consideraram que a CGC é relativamente mais importante do que a CEC, quando linhagens não selecionadas para o caráter em estudo são utilizadas. Além disso, destaca-se que não se conhece parentesco entre as linhagens no presente estudo, pois este fato diminuiria os efeitos da CEC.

Houve interação da CGC com os ambientes (Tabela 3); portanto, os efeitos da CGC não foram similares nos dois anos, o que torna importante a observação do comportamento das linhagens $\left(\hat{\mathrm{g}}_{\mathrm{i}}\right)$ em cada ano agrícola, e a prática do que se denomina de melhoramento (seleção) para condições específicas (Vencovsky \& Barriga, 1992; Nihei \& Ferreira, 2012).

A interação entre CEC e ambientes, na ausência de $P$ na semeadura, mostra que o desempenho geral das combinações híbridas diferiu entre os anos (ambientes) de 2011 e 2012, e que se deve observar os resultados dos cruzamentos em cada ano. Não houve interação significativa entre CEC e ambientes na presença de P e, portanto, os anos de 2011 e 2012 puderam ser analisados conjuntamente.

$\mathrm{Na}$ análise conjunta, com as médias dos anos de 2011 e 2012, o efeito médio $\hat{\mathrm{g}}_{\text {, }}$, na presença de $\mathrm{P}$, variou de 853,56, para a linhagem 2 (L228-3), até $-1.148,42$, para a linhagem 6 (L56.800.84). Na ausência de P, a variação foi de 931,85, para a linhagem 1 (L3), até - 787,71, para a linhagem 8 (L53) (Tabela 4). A linhagem 1 (L3) apresentou o maior efeito $\hat{g}_{\mathrm{i}}$ médio e o maior valor individual, no caso dos efeitos da 
CGC, na ausência de $\mathrm{P}$, o que mostra a alta eficiência dessa linhagem em condições de baixa disponibilidade de P. A linhagem 9 (L56.800.67) mostrou dupla aptidão, tendo apresentado, ao mesmo tempo, maior responsividade em 2012 e boa eficiência na ausência de P na semeadura. A linhagem 2 (L228-3) mostrou-se altamente responsiva à adubação com $\mathrm{P}$.

A linhagem ideal para o melhoramento deve apresentar responsividade na presença de $\mathrm{P}$ e alta eficiência em condições de baixa disponibilidade do nutriente. Em média, a linhagem 2 (L228-3) mostrouse a mais responsiva à presença de $\mathrm{P}$ e com razoável eficiência de uso. A combinação híbrida 1x2 (L3 x L228-3) representa o híbrido comercial BRS 1010, muito eficiente quanto ao uso de P (Parentoni et al., 2004), originado do cruzamento entre uma linhagem muito eficiente (L3) com outra muito responsiva (L228-3), que expressa o conceito desejável de alto $\hat{\mathrm{g}}_{\mathrm{i}}$, nos parentais, e alto $\hat{s}_{\mathrm{ij}}$ na combinação híbrida (Hallauer \& Miranda Filho, 1985; Cruz et al., 2004; Nihei \& Ferreira, 2012; Ramalho et al., 2012).

A linhagem 9 (L56.800.67), descrita como ineficiente, mostrou-se relativamente eficiente ao uso do P, o que mostra que as estimativas de CGC e CEC, bem como os resultados dos estudos de herança, são relativos. A linhagem 1 (L3) apresentou alta eficiência na ausência de P na semeadura, o que está de acordo com o fato de que esse material é uma importante linhagem da Embrapa, da qual originaram-se híbridos comerciais eficientes à baixa disponibilidade de $\mathrm{P}$, e

Tabela 4. Efeito da capacidade geral de combinação ( $\left.\hat{\mathrm{g}}_{\mathrm{i}}, \mathrm{CGC}\right)$ quanto à produtividade de grãos de milho, com ou sem o uso de $\mathrm{P}$ na adubação de semeadura, nos anos de 2011 e 2012.

\begin{tabular}{|c|c|c|c|c|c|c|}
\hline \multirow[t]{2}{*}{ Linhagem } & \multicolumn{3}{|c|}{$\hat{\mathrm{g}}_{\mathrm{i}}$ com P na semeadura } & \multicolumn{3}{|c|}{$\hat{\mathrm{g}}_{\mathrm{i}}$ sem P na semeadura } \\
\hline & 2011 & 2012 & Média & 2011 & 2012 & Média \\
\hline 1 & 422,43 & 135,75 & 279,09 & $1.247,84$ & 615,86 & 931,85 \\
\hline 2 & 859,96 & 847,16 & 853,56 & 108,85 & 231,33 & 170,09 \\
\hline 3 & 451,63 & 154,47 & 303,05 & 369,02 & $-410,28$ & $-20,63$ \\
\hline 4 & $-597,09$ & $-609,46$ & $-603,27$ & $-849,73$ & 625,26 & $-112,24$ \\
\hline 5 & 759,32 & 217,19 & 488,26 & 107,19 & $-7,05$ & 50,07 \\
\hline 6 & $-1.092,20$ & $-1.204,64$ & $-1.148,42$ & $-706,96$ & 161,79 & $-272,58$ \\
\hline 7 & $-93,12$ & 192,51 & 49,70 & $-344,70$ & $-480,20$ & $-412,45$ \\
\hline 8 & $-327,82$ & $-686,17$ & $-507,00$ & $-536,67$ & $-1.038,76$ & $-787,71$ \\
\hline 9 & $-383,12$ & 953,19 & 285,04 & 605,16 & 302,06 & 453,61 \\
\hline $\mathrm{DP} \hat{\mathrm{g}}_{\mathrm{i}}$ & 185,89 & 245,62 & - & 170,86 & 164,98 & - \\
\hline $\mathrm{DP}\left(\hat{g}_{\mathrm{i}}-\hat{\mathrm{g}}_{\mathrm{j}}\right)$ & 278,83 & 368,44 & - & 256,29 & 247,47 & - \\
\hline
\end{tabular}

DP, desvio-padrão. denota a importância do efeito per se desta linhagem e de sua capacidade combinatória.

$\mathrm{Na}$ presença de $\mathrm{P}$, o efeito médio $\hat{\mathrm{S}}_{\mathrm{ij}}$ variou de 1.279,23, para a combinação $5 \times 7$ (L51502020 x L22), até - 2.075,18, para a combinação 1x5 (L3 $x$ L 51502020). Na ausência de P, esse efeito médio variou de 1.127,66, para a combinação 3x6 (L36 x L56.800.84), até $-1.276,98$, para a combinação $4 \times 9$ (L56.800.79 x L56.800.67) (Tabela 2).

$\mathrm{Na}$ análise sobre ambientes em separado, o maior efeito $\hat{\mathrm{s}}_{\mathrm{ij}}$ (CEC) ocorreu para a combinação $2 \times 9$ (L228-3 x L56.800.67), com valores de 1.571,88, em 2012, e de 1.196,39 para a combinação 2x5 (L228-3 x L51502020), em 2011, na ausência de P na semeadura. $\mathrm{Na}$ presença de $\mathrm{P}$, os maiores efeitos foram observados nas combinações $1 \times 2$ (L3 x L228-3), com 1.661,38 em 2011, e 4x7 (L56.800.79 x L22), com 1.312,39 em 2012. O cruzamento $4 x 7$ apresentou alto efeito $\hat{s}_{\mathrm{ij}}$ na presença de $\mathrm{P}$, e bom efeito na ausência, o que é desejável. $\mathrm{O}$ efeito $\hat{\mathrm{s}}_{\mathrm{ij}}$ para o híbrido $4 \mathrm{x} 7$ indica que ocorreram desvios, em relação ao que se esperava pela CGC dos progenitores 4 e 7, e evidencia a presença de genes não aditivos (Cruz et al., 2004).

O híbrido $4 \times 7$ combina uma linhagem eficiente (linhagem 4=L56.800.79) com outra ineficiente (linhagem 7=L22), e os resultados obtidos para ele mostram a ocorrência de complementação gênica entre as linhagens (Vencovsky \& Barriga, 1992). É incomum que duas linhagens com baixa CGC resultem em combinações específicas superiores (Pinto, 2009); mas duas linhagens com alta CGC nem sempre resultam em uma combinação específica superior (Cruz \& Vencovsky, 1989), pois, para isso, é necessário haver complementação gênica e existência de dominância (Ramalho et al., 2012). A combinação $4 \times 7$ foi a segunda colocada na classificação dos $\hat{\mathrm{s}}_{\mathrm{ij}}$, na presença de $\mathrm{P}$ (Tabela 2). Na ausência do nutriente, em 2012, o cruzamento 2x9 (L228-3 x L56.800.67) foi o primeiro colocado no ranqueamento dos efeitos da CEC. Esse híbrido também envolve uma linhagem eficiente (linhagem 2=L228-3) e outra ineficiente (linhagem 9=L56.800.67), o que reforça a importância da complementação gênica.

As linhagens 1 (L3) e 5 (L51502020) podem ser consideradas como muito eficientes per se. Porém, como a linhagem desejada, além de apresentar maior efeito da CGC, também deve participar de cruzamentos com alta CEC (Cruz et al., 2004), a 
linhagem 2 (L228-3) é que deve ser considerada como muito promissora na responsividade a $\mathrm{P}$, pois apresenta alto $\hat{g}_{i}$ e participa do cruzamento de maior efeito $\hat{\mathrm{s}}_{\mathrm{ij}}$ na presença de $\mathrm{P}$. Quanto à eficiência de uso, a linhagem 1 (L3) é a mais promissora, pois, para esse caráter, ela tem o maior valor de $\hat{g}_{i}$ e participa da combinação com o maior valor de $\hat{\mathrm{s}}_{\mathrm{ij}}$, na ausência de $\mathrm{P}$ na semeadura.

No entanto, para a maioria das interações, a ocorrência de interação GxA, na análise conjunta, sugere que se selecionem genótipos específicos para cada ambiente. Dessa forma, as melhores linhagens a serem selecionadas quanto à responsividade na presença de $\mathrm{P}$, com base no efeito genético $\hat{\mathrm{g}}_{\mathrm{i}}$, são as linhagens 2 e 5 (L228-3 e L51502020), em 2011, e 2 e 9 (L228-3 e L56.800.67), em 2012. Na ausência de $\mathrm{P}$, ou seja, para a seleção quanto à eficiência de uso, as melhores linhagens com base no $\hat{\mathrm{g}}_{\mathrm{i}}$ seriam a 1 e a 9 (L3 e L56.800.67), em 2011, e as linhagens 4 e 1 (L56.800.79 e L3) em 2012.

Parentoni et al. (2010) relataram redução média de produtividade de $45,0 \%$ entre os níveis de alta e baixa disponibilidade de $\mathrm{P}$ no solo. No presente trabalho, a redução da produtividade foi de $56,4 \%$, na média dos anos de 2011 e 2012 (Tabela 2).

\section{Conclusões}

1. Os efeitos não aditivos predominam na responsividade do milho ao aumento da disponibilidade de $\mathrm{P}$, enquanto efeitos aditivos predominam na eficiência de uso do nutriente.

2. A seleção do melhor progenitor e da melhor combinação híbrida deve ser realizada em ambientes específicos, em razão da existência de interação genótipo $\mathrm{x}$ ambiente para as capacidades combinatórias.

3. A linhagem L3 apresenta o maior efeito médio da capacidade geral de combinação na ausência de $\mathrm{P}$ na semeadura, e a L228-3 na presença de P.

4. A complementariedade gênica está presente entre as linhagens e é importante para que as combinações híbridas apresentem eficiência de uso de P.

\section{Agradecimentos}

À Empresa Brasileira de Pesquisa Agropecuária (Embrapa) e à Fundação Mcknight, por apoio financeiro; aos técnicos Fábio Rabello Soares, Eduardo Elias de Faria e Orismar Aparecido Espíndola da Silva, por apoio de campo.

\section{Referências}

AGUIAR, A.M.; CARLINI-GARCIA, L.A.; SILVA, A.R. da; SANTOS, M.F; GARCIA, A.A.F.; SOUZA JR., C.L. Combining ability of inbred lines of maize and stability of their respective single-crosses. Scientia Agricola, v.60, p.83-89, 2003. DOI: 10.1590/S0103-90162003000100013.

BRASIL, E.C.; ALVES, V.M.C.; MARRIEL, I.E.; PITTA, G.V.E.; CARVALHO, J.G. de. Matéria seca e acúmulo de nutrientes em genótipos de milho contrastantes quanto à aquisição de fósforo. Ciência e Agrotecnologia, v.31, p.704-712, 2007. DOI: 10.1590/ S1413-70542007000300016.

CRUZ, C.D. GENES: a software package for analysis in experimental statistics and quantitative genetics. Acta Scientiarum. Agronomy, v.35, p.271-276, 2013. DOI: 10.4025/ actasciagron.v35i3.21251.

CRUZ, C.D. Programa Genes: Biometria. Viçosa: UFV, 2006. $382 \mathrm{p}$.

CRUZ, C.D.; VENCOVSKY, R. Comparação de alguns métodos de análise dialélica. Revista Brasileira de Genética, v.12, p.425-438, 1989.

CRUZ, C.D.; REGAZZI, A.J.; CARNEIRO, P.C.S. Modelos biométricos aplicados ao melhoramento genético. 3.ed. Viçosa: UFV, 2004. v.1, 480p.

DOVALE, J.C.; FRITSCHE-NETO, R. Genetic control of traits associated with phosphorus use efficiency in maize by REML/ BLUP. Revista Ciência Agronômica, v.44, p.554-563, 2013. DOI: 10.1590/S1806-66902013000300018.

DOVALE, J.C.; FRITSCHE-NETO, R.; BERMUDEZ, F.; MIRANDA, G.V. Efeitos gênicos de caracteres associados à eficiência no uso de nitrogênio em milho. Pesquisa Agropecuária Brasileira, v.47, p.385-392, 2012. DOI: 10.1590/ S0100-204X2012000300010.

FREITAS JÚNIOR, S. de P.; AMARAL JÚNIOR, A.T. do; PEREIRA, M.G.; CRUZ, C.D.; SCAPIM, C.A. Capacidade combinatória em milho-pipoca por meio de dialelo circulante. Pesquisa Agropecuária Brasileira, v.41, p.1599-1607, 2006. DOI: 10.1590/S0100-204X2006001100005.

FRITSCHE-NETO, R.; MIRANDA, G.V.; DELIMA, R.O.; SOUZA, L.V. de; SILVA, J. da. Herança de caracteres associados à eficiência de utilização do fósforo em milho. Pesquisa Agropecuária Brasileira, v.45, p.465-471, 2010.

GRIFFING, B. Concept of general and specific combining ability in relation to diallel crossing systems. Australian Journal of Biological Sciences, v.9, p.463-493, 1956.

HALLAUER, A.R.; MIRANDA FILHO, J.B. Quantitative genetics in maize breeding. $3^{\text {rd }}$ ed. Ames: Iowa State University Press, 1985. 468p.

MARSCHNER, H. Mineral nutrition of higher plants. $2^{\text {nd }}$ ed. London: Academic Press, 1995. 889p.

MEIRELLES, W.F. Análise dialélica de linhagens de milho em diferentes níveis de fósforo. 2013. 95p. Tese (Doutorado) Universidade Estadual de Maringá, Maringá.

Pesq. agropec. bras., Brasília, v.51, n.3, p.224-232, mar. 2016 DOI: $10.1590 / \mathrm{S} 0100-204 X 2016000300004$ 
MENDES, F.F.; GUIMARÃES, L.J.M.; SOUZA, J.C.; GUIMARÃES, P.E.O.; MAGALHÃES, J.V.; GARCIA, A.A.F.; PARENTONI, S.N.; GUIMARÃES, C.T. Genetic architecture of phosphorus use efficiency in tropical maize cultivated in a low-P soil. Crop Science, v.54, p.1530-1538, 2014. DOI: 10.2135/ cropsci2013.11.0755.

NIHEI, T.H.; FERREIRA, J.M. Análise dialélica de linhagens de milho com ênfase na resistência a doenças foliares. Pesquisa Agropecuária Brasileira, v.47, p.369-377, 2012. DOI: 10.1590/ S0100-204X2012000300008.

PARENTONI, S.N.; GAMA, E.E.G. e; SANTOS, M.X. dos; PACHECO, C.A.P.; MEIRELLES, W.F.; CORREA, L.A.; GUIMARÃES, P.E. de O.; CASELA, C.R.; FERREIRA, A. da S.; ALVES, V.M. de C.; FERNANDES, F.T.; RIBEIRO, P.H.E. Híbrido simples de milho BRS 1010. Sete Lagoas: Embrapa Milho e Sorgo, 2004. 6p. (Comunicado técnico, 107).

PARENTONI, S.N.; SOUZA JR., C.L.; ALVES, V.M. de C.; GAMA, E.E.G.; COELHO A.M.; OLIVEIRA, A.C. de; GUIMARÃES, P.E.O.; GUIMARÃES, C.T.; VASCONCELOS, M.J.V.; PACHECO, C.A.P.; MEIRELLES, W.F.; MAGALHÃES, J.V. de; GUIMARÃES, L.J.M.; SILVA, A.R. da; MENDES, F.F.; SCHAFFERT, R.E. Inheritance and breeding strategies for phosphorus efficiency in tropical maize (Zea mays L.). Maydica, v.55, p.1-15, 2010.

PINTO, R.J.B. Introdução ao melhoramento genético de plantas. 2.ed. Maringá: EDUEM, 2009. 351p.

RAMALHO, M.A.P.; ABREU, A. de F.B.; SANTOS, J.B. dos; NUNES, J.A.R. Aplicações da genética quantitativa no melhoramento de plantas autógamas. Lavras: UFLA, 2012. 522p.

RESENDE, M.D.V. de; DUARTE, J.B. Precisão e controle de qualidade em experimentos de avaliação de cultivares. Pesquisa Agropecuária Tropical, v.37, p.182-194, 2007.
SCAPIM, C.A; BRACCINI, A. de L. e; PINTO, R.J.B.; AMARAL JÚNIOR, A.T. do; RODOVALHO, M. de A.; SILVA, R.M. da; MOTERLE, L.M. Componentes genéticos de médias e depressão por endogamia em populações de milho-pipoca. Ciência Rural, v.36, p.36-41, 2006a. DOI: 10.1590/S0103-84782006000100006.

SCAPIM, C.A.; PINTO, R.J.B.; AMARAL JÚNIOR, A.T. do; MORA, F.; DANDOLINI, T.S. Combining ability of white grain popcorn populations. Crop Breeding and Applied Biotechnology, v.6, p.136-143, 2006b. DOI: 10.12702/1984-7033.v06n02a04.

SILVA, V.M.P. e; CARNEIRO, P.C.S.; MENEZES JÚNIOR, J.A.N. de; CARNEIRO, V.Q., CARNEIRO, J.E. de S.; CRUZ, C.D.; BORÉM, A. Genetic potential of common bean parents for plant architecture improvement. Scientia Agricola, v.70, p.167-175, 2013. DOI: $10.1590 / \mathrm{S} 0103-90162013000300005$.

SOUSA, S.M. de; CLARK, R.T.; MENDES, F.F.; OLIVEIRA, A.C. de; VASCONCELOS, M.J.V. de; PARENTONI, S.N.; KOCHIAN, L.V.; GUIMARÃES, C.T.; MAGALHÃES, J.V. A role for root morphology and related candidate genes in $\mathrm{P}$ acquisition efficiency in maize. Functional Plant Biology, v.39, p.925-935, 2012. DOI: $10.1071 /$ FP12022.

SOUZA, L.V. de; MIRANDA, G.V.; GALVÃO, J.C.C.; ECKERT, F.R.; MANTOVANI, E.E.; LIMA, R.O.; GUIMARÃES, L.J.M. Genetic control of grain yield and nitrogen use efficiency in tropical maize. Pesquisa Agropecuária Brasileira, v.43, p.1517-1523, 2008. DOI: 10.1590/S0100-204X2008001100010.

SPRAGUE, G.F.; TATUM, L.A. General vs. specific combining ability in single crosses of corn. Journal of the American Society of Agronomy, v.34, p.923-932, 1942. DOI: 10.2134/agronj1942.0 0021962003400100008x.

VENCOVSKY, R.; BARRIGA, P. Genética biométrica no fitomelhoramento. Ribeirão Preto: Revista Brasileira de Genética, 1992. 486p.

Recebido em 22 de junho de 2015 e aprovado em 2 de fevereiro de 2016 